\title{
AURORA GÓMEZ-GALVARRIATO
}

Rosenzweig, puerta abierta entre Economía e Historia.

$\mathbf{F}$

ernando Rosenzweig, hombre político, funcionario público y no se si economista de la historia, historiador de la economía o sim-. plemente historiador y economista, fue además un verdadero maestro de tiempo completo. Con esto quiero decir que el ser profesor no era para él una profesión, un trabajo, una actividad que debía desempeñar durante algunas horas; sino que el ser maestro era en él como el ser hombre, como el ser mexicano, una característica de su persona que estaba siempre presente, pues cualquier palabra intercambiada con él y su vida misma eran una enseñanza; y en el sentido más correcto se diría no que fue un profesor sino que lo es, ya que su ejemplo y alguna parte de sus enormes conocimientos siguen aquí con nosotros.

Sus cursos eran como un relato, como un cuento. No daba clase, conversaba, charlaba. Me hacía pensar en la forma de transmisión del conocimiento de la antigüedad o de las pequeñas comunidades; el Maestro (con mayúscula), la persona que ha vivido más, que comunica a los jóvenes las historias de su pueblo, su sabiduría; los jóvenes que lo escuchan y respetan.

Fernando Rosenzweig abría con gran facilidad una puerta que pocos abren y a la que muchos ponen candados, la puerta entre la economía y la historia, y al hacerlo enriquecía ambos espacios. Escucharlo era entrar a un territorio que no podría llamar fantástico, pues precisamente su maravilla radicaba en que era real, verdadero, era historia. Su rigurosidad científica siempre estaba presente, era clara su pasión por la verdad que hacía a su historia ajena a posturas pro-sistema o anti-sistema. La suya no era una historia de héroes sino de hombres, y más que de hombres de acciones, de decisiones indivi-

- Departamento de Economía, ITAM. 
duales y colectivas, que eran las únicas susceptibles de ser analizadas y juzgadas. Así cada régimen, estaba lleno de aciertos y errores y se dejaba de lado la historia de los buenos y los malos.

Lo más impresionante de escucharlo era que se le podía preguntar y preguntar y siempre había un conocimiento más allá, más profundo. Era como pasar de una habitación llena de puertas a otra con todavía más puertas, habitaciones y puertas que se sucedían unas a otras y que parecían no tener fin. Debido a esto el curso, con todas sus riquezas, nos dejaba muchas veces con el sentimiento de estar apenas en la corteza de un enorme territorio.

Afortunadamente siempre había otros recursos. Encontrárselo en los pasillos del ITAM era recibir un puñado de afecto y comenzar una conversación fascinante que generalmente se prolongaba en su cubículo, en donde era muy visitado. El tema de la plática era lo de menos, se le podía hacer cualquier pregunta, la más simple o la más compleja, y muchas veces ni siquiera eso era necesario, algún tema salía. Y entonces uno entraba al mundo de las alcabalas, de la exportación de la cochinilla, de los estancos de naipes y de nieve del Popocatépetl, de la Revolución inglesa, de la sustitución de importaciones durante el Porfiriato, de la hiperinflación revolucionaria, del desarrollo estabilizador, de la deuda... Y icuánto aporta todo esto para comprender al México actual! La plática siempre había de acabar por una razón externa porque en sí era interminable.

Luego, a los días, al volver a encontrarlo, frecuentemente ocurría que tuviera un paquete especial para nosotros. Una alta pila de libros (algunos muy viejos, lo cual la hacía más interesante) acerca del tema de la vez anterior, de la pregunta aquélla. Me sigue encogiendo el corazón pensar en que ese hombre con tanto trabajo y preocupaciones, se acordara de nuestras inquietudes, de nuestras preguntas, y buscara en su biblioteca, que imagino inmensa, los libros que nos pudieran servir, interesar o simplemente gustar; que los llevara al ITAM y dejara por ahí en una esquina esperándonos.

"¿Por qué sirve el estudio de la historia?" preguntó en su primera clase, y citó a Ortega y Gasset, Justo Sierra, Lucas Alamán. La historia es la explicación de lo que somos, la comprensión de lo que hemos sido. El hombre tiene varias posibilidades acerca de lo que puede ser; la historia le ayuda a decidir hacia dónde dirigirse.

¿Y la historia económicá? Se refirió entonces a la historia económica marxista, a la escuela francesa de Braudel, ' a la historia cuanti- 
tativa, a la Escuela de los Anales. Fernando Rosenzweig consideraba muy importantes también los esfuerzos de los economistas (como el de Douglas North, por ejemplo) por penetrar en este campo. Lo cuantitativo debe ser gobernado por una visión teórica, decía. Es muy importante además, tener una noción precisa y clara de que los fenómenos económicos tienen muchas veces orígenes no económicos.

Si queremos comprender por ejemplo, las vicisitudes del desarrollo económico en América Latina, si queremos hacer una comparación entre América Latina y los países desarrollados, decía; no podemos prescindir del instrumental neoclásico, pero debemos estar conscientes de que tampoco funciona totalmente. Las ideologías y estructuras políticas influyen a la economía; así la economía debe reestablecer peculiaridades históricas y políticas.

La historia económica, para Don Fernando, debía abocarse al estudio de dos órdenes esenciales. En primer lugar debe estudiar los aspectos referentes al producto, al cómo se produce, qué se produce, quiénes producen y cómo se reparte lo que se produce, a la maxim. . zación sujeta a restricciones que se da en el proceso productivo y de intercambio. En este ámbito es donde él consideraba que funciona el mundo neoclásico. Sin embargo existe otro aspecto, para él muy importante, que es el de estudiar la estructura de la actividad producti$\mathrm{va}$, los factores que dentro del cuadro institucional determinan el cómo se establece y protege la propiedad, cuestiones sobre las instituciones, la política y la ideología, fenómenos políticos y sociales para los cuales tenemos que recurrir a explicaciones ajenas a la economía para luego integrarlos al pensamiento económico. Estos dos aspectos conformaban su ámbito de estudio.

Al hacer historia económica había en primer lugar que poner en orden los hechos. Después había que hacer una serie de hipótesis acerca de los mismos. Y finalmente había que hacer interactuar las hipótesis con el estado de conocimientos y los datos que conocemos de la realidad. Este era su método de estudio, que como vemos, refleja un gran amor por la ciencia y por la búsqueda de la verdad.

Era frecuente verlo inquieto, llamado por la curiosidad a la búsqueda de algo. Así recuerdo haberlo visto trabajando sobre un escritorio lleno de libros refutando las ideas propuestas por Hernando De Soto en el libroEconomía subterránea. Este libro tiene buenas ideas, decía, pero muchas de sus afirmaciones simplemente no concuerdan con la historia del Perú, y específicamente con su historia económica; 
historia que Don Fernando conocía a la perfección, pues vivió en ese país durante algún tiempo.

Las inquietudes de Fernando Rosenzweig eran enormemente constructivas sobre todo porque él era una de esas escasas personas dispuestas a ver la realidad tal cual, y que sólo después de haberla aprendido tratan de explicarla. Especialmente en estos días, cuando en México los pensamientos se dividen entre dos esterotipos maniqueos: el "cardenista", favorecedor de la intervención estatal, protector del estado benefactor y el neo-liberal, favorecedor del libre mercado y de un estado mínimo; y sobre todo cuando los pensamientos parecen colocarse en una de estas dos casillas por "convicción" muchas veces irracional, y no por un análisis de las situaciones específicas, personas como Don Fernando son especialmente valiosas. Además, nunca dejó envejecer a sus pensamientos, estaba al tanto de todo lo nuevo en economía, historia, filosofía... y cuentan haberlo visto estudiando libros de álgebra y cálculo que revisaba para no dejar sin entender algún artículo reciente de economía.

Siendo un gran preocupado por el devenir del campesino mexicano, Fernando Rosenzweig ocupaba gran parte de su tiempo tratanto de comprender el proceso de desarrollo del agro, la causa de su retraso, su relación con el desarrollo industrial de nuestro país, su estructura de propiedad y todos los demás aspectos imaginables. Le había surgido una gran cuestionante: ya no podía estar seguro de los grandes méritos del ejido, se preguntaba si esta estructura de propiedad había sido un retroceso o un avance para México. Esto le preocupaba, no lo dejaba tranquilo y lo llevaba a estudiar más y más. Cuando esta pregunta se plantea tratando de contestarla con la historia y la economía dejando a un lado la ideología ("revolucionaria" o "reaccionaria"), es sin duda una pregunta muy difícil e interesante. Este acto, habla del gran profesionalismo de Fernando Rosenzweig, de su fuerte convicción por la verdad y de su enorme preocupación por sacar adelante a este país, buscando soluciones en todos los espacios posibles; pues alguien que admiraba profundamente a Lázaro Cárdenas, y quien en su juventud formó parte del Partido Socialista siendo seguidor de Lombardo Toledano, difícilmente se podría cuestionar un asunto como éste.

El profesor Rosenzweig era un hombre que podía estar, como de hecho lo hacía, tanto investigando acerca de la historia del Estado de México, su tierra natal, como haciendo una propuesta de política 
agraria al Gobierno de la República. Era un gran entusiasta que siempre recibía con gusto las inquietudes de los estudiantes, para hacer desde conferencias y organizaciones estudiantiles hasta un banco de datos computarizado sobre estadísticas históricas de México, y siempre era un gran apoyo.

Don Fernando, como ya hemos podido elucidar en las anteriores líneas, fue una persona profundamente preocupada por México, le inquietaba nuestro futuro. Estaba siempre en la búsqueda de respuestas a tantas preguntas, que nunca le alcanzaría la vida para contestar. Sus reflexiones, que al estar sólidamente fundamentadas en un amplio conocimiento de pasado y presente, resultan de un amplio valor, constantemente vuelven a sonar en mis oídos.

Casi podría oír su voz cuando decía "¿Estamos haciendo el mejor uso de los recursos; y las necesidades que estamos satisfaciendo son las correctas?"

"Nos encontramos en una situación en la que los viejos esquemas del pasado, sustitución de importaciones, desequilibrio fiscal, subsidios basados en una inhibición del desarrollo del sector agropecuario se han roto. Tenemos también la experiencia de la época de Porfirio Díaz en la que el esquema moderno de industrialización se detuvo, pues estaba basado en un país anclado en su desarrollo por el predominio del latifundio que hizo imposible generar una demanda interna lo suficientemente grande."

"Al seguir la política de sustitución de importaciones", decía, "nunca nos preguntamos si estábamos satisfechos con el esquema actual de consumo y si por tanto debía conservarse; sólo tratamos de cubrirlo con oferta nacional. Ahora nos damos cuenta que los esquemas de sustitución de importaciones eran demasiado simplistas, había que producir todo lo que se importara y nunca se pensó en las ventajas comparativas o en la integración vertical de determinadas industrias. Tenemos que cambiar de estrategia."

"Nos damos cuenta que la exportación de materias primas no genera los recursos suficientes que el país necesita, hay que exportar manufacturas pero icómo volvernos más eficientes?", preguntaba.

Casi podría repetir textualmente sus palabras: "Requerimos un esquema, en el que sepamos cuáles son las diez industrias en las que debemos de colocar nuestros recursos. Es de suma importancia tener bien discernidas cuáles con las prioridades a las cuales debe dirigirse el esfuerzo del pais; no hay que perder el rumbo y nunca hay que ol- 
vidar que el objetivo principal de la política económica es el satisfacer las necesidades básicas de la población, la demanda de las grandes masas; para lograrlo debemos generar los bienes primarios que podamos producir con eficiencia, y esto hace necesaria la tecnificación del campo".

Le preocupaba mucho que la política económica mexicana se concentrara en el corto plazo especialmente en momentos de cambio como éste, cuando había que fijarse en el largo plazo. "Es necesario considerar la utilización de los recursos que el país necesita para expandir su producción y dada la magnitud de la deuda externa resulta de suma importancia plantearla dentro de un contexto de largo plazo que no se resolverá con medidas limitadas como el cierre de algunas plantas", decía.

En alguna clase Fernando Rosenzweig comparaba el proceso de desarrollo e industrialización mexicano con el inglés; esta contrastación explica muchos aspectos de nuestro subdesarrollo. "El esquema de la revolución inglesa", decía, "fue el crear una industria para satisfacer las demandas crecientes de la población. En este proceso, se dio una época muy dinámica en la que la clase empresarial inglesa respondió, creando una industria moderna. En ese período se tuvo una máxima capacidad creativa que decayó con el tiempo, cuando los empresarios se aristocratizaron y buscaron la vida señorial en lugar de la innovación, en ese momento Inglaterra también comenzó a decaer." "En México, a lo largo de nuestra historia si bien han existido algunos empresarios excepcionales, el común de éstos han buscado siempre la vida señorial, y por tanto no le han respondido al país."

"Esto", decía, "nos lleva a una reflexión muy importante, ya que los planteamientos de la política económica actual suponen que van a existir agentes económicos: los empresarios, que van a buscar la adecuada combinación de recursos. El empresario mexicano sin embargo, a lo largo de la historia no ha demostrado mucha eficiencia. $\mathrm{Ha}$ existido siempre en nuestro país una falta de capacidad empresarial".

Explicaba cómo durante el desarrollo estabilizador se cayó en un esquema en el que acostumbramos a los empresarios mexicanos al "apapachamiento", por medio de una actitud paternalista en la que se otorgaban beneficios sin contrapartida, en la que nos acostumbramos al favor y no a la eficiencia. "Esquema del cual", decía Rosenzweig, "todavía no hemos logrado salir completamente. Necesitamos espíritu de eficiencia." 
Estas reflexiones nos hacen percatarnos de la gran complejidad inmersa en el planteamiento de un esquema de desarrollo para nuestro país. ¿Cómo dotarnos de un nivel adecuado de capacidad empresarial, insumo básico para el desarrollo, que al ser tan escaso requiere de la intervención del estado, y que al mismo tiempo es inhibido por esa misma intervención estatal? ¿Cómo diseñar un sistema de tenencia de la tierra que asegure eficiencia a la vez que equidad, esto es, que asegure un nivel de vida digno para todos los habitantes del campo? Fernando Rosenzweig no dió todas las respuestas, sin embargo nos dejó dos grandes enseñanzas.

En primer lugar nos hizo percatarnos de que si de algo podemos estar seguros es de que la solución no está en todo o nada. Que no existen fórmulas simples (que resultarían simplistas), para problemas tan complejos, y que tampoco existe una sola respuesta para todas las preguntas, una sola receta para todos los problemas. Que la realidad es demasiado rica y variada para poder captarla toda con un solo esquema y que si usamos un solo aparato veremos sólo una parte de ella. Nos enseñó que hay que analizar cuidadosamente cada problema específico y buscar soluciones concretas no sólo mirándolo desde un punto de vista económico sino también político y social; buscando esas soluciones con la mente lo más abierta posible y escapando de cualquier dogmatismo.

La segunda enseñanza, es que la historia económica es un buen lugar para buscar preguntas y respuestas que nos ayuden a construir el futuro. El estudio de la historia económica, como él mismo decía, nos hace percatarnos de la existencia de todos aquellos factores no económicos que influyen en la ecnomía: ideología, instituciones...; y que si son olvidados llevarán al fracaso de las políticas públicas. Su estudio nos hace además percatarnos de la importancia relativa de los distintos fenómenos económicos en la explicación de los sucesos de distinto orden: políticos, sociales, culturales; lo que nos lleva a una mejor comprensión de nuestro pasado. La historia económica de esta forma nutre tanto a la economía como a la historia. El estudio de la historia económica, además, nos ayuda a entender mejor el sentido que lleva nuestro desarrollo y el rumbo que debería seguir, ya que fuerza a quien la estudia a salirse del corto plazo y ampliar el horizonte temporal, a ver los hechos como parte de un conjunto más amplio que muchas veces les otorga el sentido del que carecen cuando se ven por sí solos. 
He recorrido las notas que tomé en su curso y me doy cuenta de cuántas ideas nuevas me aportó, ideas que hoy forman parte de mí de una manera tan natural que ni siquiera recordaba de dónde habían venido. Estoy segura que muchos de estos conceptos son innovaciones, descubrimientos, aportaciones originales de Fernando Rosenzweig, producto de una investigación que sólo él ha hecho. Alguna parte de su pensamiento y trabajo está publicado, otra no. Creo que el recopilar sus ideas sería una labor sumamente valiosa. Sin embargo, se logren recopilar o no, Don Fernando fue un Maestro y sobre todo, como antes dije, es un Maestro. Así, su legado persiste y persistirá en aquellos que tuvimos una vez la fortuna de convivir con él. 